\title{
Functional Assessment of Incontinence Therapy-Fecal
}

National Cancer Institute

\section{Source}

National Cancer Institute. Functional Assessment of Incontinence Therapy-Fecal. NCI

Thesaurus. Code C120177.

A symptom-specific subscale of the FACIT scales that is used to assess how fecal incontinence interferes affects an individual's life. 